Mary Yale Rodrigues Neves (iD) https://orcid.org/0000-0002-9821-3826

Hélder Pordeus Muniz ${ }^{\mathrm{b}}$

(iD) https://orcid.org/0000-0001-8430-3647

Denise Alvarez

(iD) https://orcid.org/0000-0002-3216-3993

Marcelo Gonçalves Figueiredo ${ }^{c}$

(iD https://orcid.org/0000-0001-5612-2929

Maristela Botelho França ${ }^{d}$

(iD) https://orcid.org/0000-0002-3688-8932

a Universidade Federal Fluminense, Instituto de Psicologia, Departamento de Psicologia. Niterói, RJ, Brasil.

b Universidade Federal Fluminense, Departamento de Psicologia, Programa de Pós-graduação em Psicologia. Niterói, RJ, Brasil.

'Universidade Federal Fluminense, Departamento de Engenharia de Produção, Programa de Pós-Graduação em Engenharia de Produção. Niterói, RJ, Brasil.

'Universidade Federal do Estado do Rio de Janeiro, Departamento de Processos Técnicos e Documentais. Rio de Janeiro, RJ, Brasil.

Contato:

Hélder Pordeus Muniz

E-mail:

heldermuniz@uol.com.br

\section{A formação como estratégia de pesquisa e intervenção em saúde do trabalhador}

\author{
Training as a research and intervention strategy \\ in occupational health
}

\section{Resumo}

Este ensaio tem como objetivo refletir acerca de contribuições teóricometodológicas que possibilitaram a composição de uma "caixa de ferramentas" para o desenvolvimento de pesquisas e intervenções nos mundos do trabalho articuladas a estratégias de formação de trabalhadores. Inicialmente, coube destacar a influência do patrimônio construído no Brasil pelos movimentos de educação popular e da saúde do trabalhador, que preconizam uma cooperação crítica entre intelectuais e trabalhadores visando à transformação das situações de vida e trabalho. Nessa direção, mostrou-se fundamental a incorporação do "ponto de vista da atividade" e a proposição do dispositivo Comunidade Ampliada de Pesquisa e Intervenção (CAPI), com vistas ao desenvolvimento de práticas de formação que contribuem para a promoção da saúde a partir das situações de trabalho. Tal encaminhamento aposta na produção de meios de análise e de transformação do trabalho conduzidos pelos próprios trabalhadores (desenvolvendo sua capacidade investigativa), em diálogo com os pesquisadores profissionais. Isso demonstra a valorização de um patrimônio comum de conceitos, mas, principalmente, de uma perspectiva ética e epistemológica segundo a qual a compreensão $\leftrightarrow$ transformação das situações de trabalho e a promoção da saúde somente são possíveis por intermédio da sinergia entre os saberes das disciplinas e aqueles investidos na atividade.

Palavras-chave: saúde do trabalhador; formação de trabalhadores; atividade de trabalho; Comunidade Ampliada de Pesquisa e Intervenção; promoção da saúde.

\section{Abstract}

This essay aims at reflecting on the theoretical-methodological contributions that enabled the production of a "tool box" for supporting research and interventions articulated with workers' training strategies. We started by highlighting the influence of the social capital built in Brazil by the popular education and workers' health movements, which advocate a critical cooperation between intellectuals and workers, aspiring to transform life and work situations. In this direction, it was fundamental to incorporate the concepts and practices of "the point of view of the activity" and of the Expanded Research and Intervention Community (CAPI - Comunidade Ampliada de Pesquisa e Intervenção) to develop training practices that lead to health promotion through work situations. Such approach recognizes that the workers themselves, by exchanging experiences with the researchers, and through the development of their investigative capacity, can produce means of analysis and of work transformation. It demonstrates the value of a common patrimony of concepts and, particularly, of an ethical and epistemological perspective according to which the understanding $\leftrightarrow$ transformation of work situations and health promotion are only possible through the synergy between the disciplines knowledge and the cognizance invested in the activity.

Keywords: occupational health; workers training; work activity; Expanded Community of Research and Intervention; health promotion. 


\section{Introdução}

O objetivo deste ensaio é refletir acerca do conjunto de contribuições epistemológicas e teórico-metodológicas que levou à composição de uma "caixa de ferramentas" necessária para o desenvolvimento de pesquisas e intervenções nos mundos do trabalho, articulada a estratégias de formação de trabalhadores. No curso de tal encaminhamento, merece destaque a aposta no "ponto de vista da atividade" e no dispositivo "Comunidade Ampliada de Pesquisa e Intervenção" (CAPI), conforme apresentados adiante.

Inicialmente, cabe destacar a influência do patrimônio construído no Brasil pelos movimentos de educação popular e da saúde do trabalhador, que preconizam uma cooperação crítica entre intelectuais e trabalhadores visando à transformação das situações de vida e trabalho.

A partir dos anos de 1970, no contexto latino-americano e em especial no Brasil, em função do impulso adquirido pelos movimentos de cunho social-popular e por suas organizações frente à ditadura civil-militar, determinados setores da intelectualidade perceberam a exigência de fortalecimento do processo educativo que se "reinventava" no seio desses novos espaços. Houve o nítido resgate da concepção inicialmente gestada no âmbito da educação de adultos por Freire ${ }^{1}$, na década de 1960, que gerou contribuições diversas em outras áreas. Ressaltamos aqui os estudos de Brandão ${ }^{2}$, Bezerra ${ }^{3}$ e Garcia ${ }^{4}$, que repercutiram diretamente na formação inicial de alguns dos autores deste texto ${ }^{5}$.

A segunda metade da década de 1970 e o decorrer dos anos 1980 marcam uma fase de predomínio da ascensão política dos movimentos sociais populares no Brasil. Configura-se, então, uma mudança quantitativa e qualitativa em sua dimensão organizacional: eles se tornam mais expressivos; multiplicam-se em novas formas de luta; renovando-se, também, movimentos já tradicionais, como as lutas de trabalhadores rurais e de sindicatos nos meios urbanos ${ }^{6}$.

Segundo Garcia ${ }^{4}$, cabe às práticas de educação popular propiciar a elaboração e a apropriação de um saber-instrumento que busque a transformação social das condições de vida e trabalho. Para tanto, como afirmado por Freire ${ }^{1}$, priorizava-se em todo o processo educativo o efetivo protagonismo de todos aqueles, trabalhadores ou não, envolvidos nesse processo, a partir da articulação de distintos saberes.

Já na construção do campo da saúde do trabalhador, iniciada na década de 1980 pelos movimentos sociais que pautavam a reforma sanitária no Brasil, foi fundamental a participação de profissionais da saúde. Estes, por sua vez, partilhavam uma compreensão integradora do processo saúde-doença ${ }^{7-8}$, no que tange à articulação entre a divisão de classes sociais e o processo de trabalho ${ }^{9}$, na esteira da tradição marxista. Passa-se a compreender os serviços de saúde como dispositivos que visam também à promoção desta por meio do auxílio à transformação das condições de vida e de trabalho realizada pelos próprios usuários em parceria com os profissionais desse setor ${ }^{10-11}$.

Ocorreram experiências de atuação sindical, e também no seio de administrações municipais, que politizavam a relação entre saúde e trabalho, tendo a transformação das condições de trabalho como elemento mobilizador de certas categorias profissionais. Foram realizadas intervenções diretas nos processos de trabalho, e existia a percepção de como esses se articulariam aos processos de saúde-doença - articulação que se nutriu, em boa medida, dos materiais da Medicina Social Latino-americana ${ }^{7}$. Essas práticas advogavam a participação dos trabalhadores como sujeitos portadores de uma experiência fundamental para a compreensão e a transformação das situações de trabalho ${ }^{11-13}$. Assim, tornou-se fundamental uma prática formativa que integrasse a experiência dos trabalhadores ao processo de promoção da saúde. Nesse movimento, foi decisiva a influência do Modelo Operário Italiano (MOI) de luta pela saúde e pela produção de conhecimento ${ }^{14}$. O MOI, além de propor instrumentos de pesquisa e intervenção, como o mapeamento de riscos, preconizava uma mudança de paradigma na forma como profissionais de saúde e trabalhadores cooperariam entre si, tendo em mira a pesquisa e a transformação do trabalho. Nessa interação os trabalhadores eram tidos como protagonistas no processo de produção de saberes e na luta pela saúde, e não apenas como meros informantes ${ }^{15-16}$.

Faz-se oportuno aqui um breve parêntese também acerca de nossa gradativa afiliação à formulação desenvolvida por Canguilhem ${ }^{17}$, cuja noção de saúde mostrou-se muito fértil e esclarecedora para o processo de análise do trabalho (sob a ótica da atividade, como afirmado adiante) e da saúde dos trabalhadores. Em verdade, primeiramente, encontramos amparo nos apontamentos de Dejours, Dessors e Desriaux ${ }^{18}$, que apreendem a saúde como um movimento de luta no sentido de ampliação cada vez maior das possibilidades de negociação entre os humanos e suas condições de vida e trabalho. Além disso, ao problematizar a relação saúde-trabalho, esses autores defendem que este último jamais é inócuo no tocante à saúde, tanto podendo beneficiá-la quanto contribuir para possíveis processos de adoecimento. Eles afirmam que a saúde é algo que se conquista, sendo fundamental o papel de cada um para tanto.

Nesse percurso, a exigência ulterior de aprofundarmos o debate em torno da noção de atividade 
humana nos conduziu a fazer uso das contribuições de Canguilhem ${ }^{17}$. O médico-filósofo concebe a saúde como uma característica fundamental do vivente, que consiste na possibilidade de tolerar infrações à norma habitual, de lidar com as infidelidades do meio e de produzir novas normas de vida. Logo, a saúde não deve ser confundida com a normalidade, posto que nesse registro o vivente apenas pode estar bem adaptado enquanto as condições daquele meio se mantiverem estáveis, revelando-se a doença no momento em que as mudanças do meio questionarem as normas de vida daquele vivente, sem que ele consiga tolerar essas alterações. Canguilhem ${ }^{17}$ afirma, portanto, que a vida é atividade (o predomínio desta), em oposição à inércia e à indiferença. Essa atividade faz com que a relação do vivente com o meio não seja de mera adaptação, já que este procura reconfigurar o meio e rearranjá-lo segundo os valores que lhe são fundamentais para viver.

Somando-se a tais contribuições, a partir de 1990 foram sendo incorporados em nossa "caixa de ferramentas" epistemológicas e teórico-metodológicas aportes em que o "ponto de vista da atividade" ocupa um lugar central nas práticas por nós desenvolvidas, que têm como horizonte a promoção da saúde a partir das situações de trabalho ${ }^{19}$.

\section{O "ponto de vista da atividade"}

No que concerne à adoção do "ponto de vista da atividade", que se confunde com o desenvolvimento da ergonomia da atividade ${ }^{20-22}$, este foi se constituindo e se consolidando, gradativamente, como o eixo norteador e aglutinador de coletivos de pesquisadores dos quais fazem parte os autores deste texto. O "olhar à lupa" da ergonomia evidenciou que o trabalho real era sempre, em algum nível, diferente do trabalho prescrito. Dessa forma, para que as fábricas pudessem operar, evitando a emergência de panes, era indispensável que os operários adaptassem as prescrições à realidade, fazendo regulações nas tarefas a partir da atividade, com suas variabilidades sempre presentes ${ }^{20-21}$. Esse "olhar" contribuiu para lançar novas luzes sobre o curso do trabalho, o qual sempre envolveria microdecisões, atestando que a gestão não se circunscreve à gerência, mas também é realizada pelo conjunto de trabalhadores. Por ser uma "arte" da intervenção, como defende Wisner ${ }^{21}$, baseada na interdisciplinaridade e tendo como objeto a atividade, essa inspiração epistemológica e teórico-metodológica facilitou muito o diálogo entre nós, oriundos de diferentes formações de base. Duraffourg ${ }^{23}$ destaca a importância do uso do "ponto de vista da atividade" como referência basilar ao relatar sua experiência em intervenção ergonômica com diferentes profissionalidades, já que essa opção contribuía para organizar as peças de um quebra-cabeça.

Nessa direção, desde 1998 também foi incorporada a nossos estudos e intervenções a démarche conceitual, ética e epistemológica da ergologia ${ }^{24-25}$. Articulando as contribuições de Canguilhem com os materiais da ergonomia da atividade, Schwartz ${ }^{24}$ afirma que embora seja indubitável a (pré-)existência de normas antecedentes (prescrições, valores, regras, procedimentos), o trabalho nunca é apenas lugar de repetição. Isso porque os indivíduos renormatizam sua atividade, enfrentando as circunstâncias e os desafios singulares que se apresentam.

Ademais, o debate de normas ocorre estreitamente perpassado por um mundo de valores. Existe, inexoravelmente, uma interface com os valores por intermédio dos quais se elege para trabalhar uma dada norma em detrimento de outra, o que é bastante complexo. Pois se no caso das normas, com frequência, verifica-se um antagonismo entre elas, no que tange aos valores pode-se lidar com aqueles que são distintos em uma mesma escolha. Schwartz ${ }^{26}$ distingue os chamados valores mercantis, dimensionáveis, daqueles que em sua origem não seriam passíveis de dimensionamento, como saúde e educação. Ele salienta que, para atribuir uma dimensão aos que se encontram nesse segundo nível, devemos nos ancorar na história concreta, tanto pelos estamentos que concebem as políticas de governo, como pela via das atividades concretas dos trabalhadores em seu percurso laboral. Esse autor argumenta que existem negociações de eficácias para construir a gestão coletiva do trabalho que vão possibilitar a constituição de renormatizações de modo não individualizado, estabelecendo acordos, de forma que tais renormatizações não se manifestem em uma dinâmica em que cada qual decide somente por si, mas na sinergia da produção de um legado histórico-coletivo.

Assumir o trabalho enquanto atividade coletiva de debate de normas num mundo de valores (e não apenas enquanto cumprimento de tarefas) exige uma postura ética e epistemológica. Um posicionamento que ajude a compreender e a transformar o trabalho em parceria com os que vivem as situações, tornando-se necessário constituir um ponto de vista da atividade. Os próprios trabalhadores, muitas vezes, falam do seu trabalho sem, no entanto, lograr a constituição desse ponto de vista. Não se trata apenas de saber a opinião deles sobre seu trabalho, mas sim de envolvê-los numa construção conjunta de análise de sua atividade para enfrentar diferentes problemas da gestão do trabalho.

Desse modo, as estratégias de pesquisa, formação e intervenção realizadas e/ou que estiveram sob nossa orientação nas últimas duas décadas, com 
diferentes segmentos do conjunto de trabalhadores, vêm se valendo da constituição de dispositivos dinâmicos de três polos (DD3P). Assumimos o arranjo proposto por Schwartz ${ }^{24}$ em que é necessária a convocação do polo dos saberes organizados e disponíveis, o dos conceitos, que podem antecipar parte da realidade, embora sempre em desfasagem com relação a esta. Entretanto esse registro dos saberes formalizados $\left(1^{\circ}\right.$ polo) deve levar em conta, inexoravelmente, a capacidade de renormatização da atividade dos humanos, algo que denota a singularidade presente em todas as situações de trabalho, de tal forma que não há como compreendê-las sem o acesso à experiência dos trabalhadores. É fundamental, nesse sentido, considerar o polo das forças de convocação e validação: o dos saberes investidos na atividade $\left(2^{\circ}\right.$ polo). Esse diálogo maiêutico em duplo sentido - já sinalizado, em momento anterior, no âmbito da própria ergonomia ${ }^{27-28}$ - apresenta-se como um princípio relevante que será representado melhor por um $3^{\circ}$ polo, o das exigências éticas e epistemológicas $^{24}$, que Duraffourg ${ }^{23}$ reivindica ser o polo da política.

Em suma, para que um dispositivo de pesquisa, formação e intervenção seja efetivo e se mostre consistente, é necessário que profissionais de pesquisa e trabalhadores que estão investigando sua própria atividade construam um valor comum e que este seja pautado pela ideia de que todos são, em alguma medida, normativos e dotados da capacidade de produzir saberes fundamentais para um processo de compreensão $\leftrightarrow$ transformação das situações de trabalho. Deve-se pressupor como postura o exercício da abertura no diálogo com o outro ${ }^{24}$. Se é importante a construção coletiva dos objetivos da pesquisa e da formação, também é imprescindível que os meios aí presentes permitam essa confrontação fundamental de saberes, tanto para a produção desses saberes como para a transformação do trabalho.

Contudo, como mencionado anteriormente, lembramos que, antes de recorrermos aos materiais da démarche ergológica, já trabalhávamos, desde os anos 1980, com a referência da "comunidade científica ampliada" proposta pelo MOI ${ }^{14}$. A importância da relação entre conceitos e experiência já estava presente nessa orientação, mas Schwartz ${ }^{29}$, ao mesmo tempo em que valoriza e se inspira nesse paradigma, salienta que a realidade atual exige reformulações, como veremos a seguir.

\section{O dispositivo "Comunidade Ampliada de Pesquisa e Intervenção" (CAPI)}

Oddone, Re e Briante ${ }^{14}$ propunham uma pesquisa baseada em uma nova concepção de produção de saber acerca do trabalho. Assim, operários e pesquisadores buscaram construir uma linguagem comum e um saber que viabiliza e agencia a compreensão e a intervenção em saúde nos locais de trabalho, desenvolvendo a noção de "comunidade científica ampliada".

Schwartz ${ }^{29}$ tece algumas críticas a essa noção, sinalizando que o termo "científica" pode engendrar incompreensões ao salientar o primado do conhecimento científico e ao limitar as virtudes e possibilidades de alternativas distintas de pesquisa e produção de saberes, como as provenientes da experiência dos trabalhadores. Além disso, ressalta que se faz necessário maior discernimento em torno dos requisitos e das atribuições tanto dos pesquisadores profissionais quanto dos vários protagonistas dos mundos do trabalho. Isso porque em pesquisas baseadas no diálogo entre saberes formais e informais tais protagonistas se tornam também pesquisadores, mas não passam a ser especialistas e cientistas. Para Schwartz ${ }^{24}$, além dos polos que englobam os saberes das disciplinas e aqueles investidos na atividade, é imprescindível levar em conta, como dito anteriormente, um terceiro polo, o qual modula a colaboração e o embate entre os outros dois: o da exigência ético-epistemológica. Essa cooperação pluridisciplinar e interprofissional requer uma conduta de humildade epistemológica, acompanhada de desconforto intelectual, demandando abertura para reelaborar tanto os conceitos das disciplinas quanto os saberes da experiência.

Diante dessa discussão, cabe lembrar que a formação social brasileira gera desafios singulares. Com efeito, tem-se uma parcela considerável de trabalhadores que possuem uma formação escolar precária, propiciando um quadro que, por vezes, pode se traduzir em dificuldades de compreensão de determinados conteúdos, de leitura e de escrita. Soma-se a isso uma tendência à desvalorização social de qualquer trabalho que não requeira formação técnica e universitária. De todo modo, é importante enfatizar que, felizmente, tais desafios não se apresentam como intransponíveis no que tange à dinâmica das CAPI, a qual mobiliza também saberes produzidos pela experiência desses trabalhadores que são potentes para a transformação. Para tanto, é essencial criar as condições que garantam efetivamente a cooperação e o diálogo entre diferentes atores.

Nessa direção, a especificidade da proposta sob forte influência do patrimônio construído no Brasil pelos movimentos de educação popular e da saúde do trabalhador - e as críticas pertinentes de Schwartz a propósito da expressão adotada no MOI justificaram a necessidade de nomear de outra forma o dispositivo que se adotou na experimentação intitulada Programa de Formação, Gênero e Trabalho nas Escolas. Tal encaminhamento resultou na denominação "Comunidade Ampliada de Pesquisa" 
(CAP) ${ }^{30-33}$. Tendo como epicentro o Programa de Formação, a CAP veio a ser denominada, alguns anos depois, "Comunidade Ampliada de Pesquisa e Intervenção" (CAPI) ${ }^{32}$, sinalizando, em sua própria nomenclatura, a dimensão da intervenção, já indicada anteriormente.

O emprego do vocábulo "comunidade" em tal dispositivo reitera seu viés tributário de iniciativas importantes, como a proposição de Oddone, Re e Briante ${ }^{14}$ e a tradição da educação popular no cenário brasileiro, experiências que afirmaram a relevância do diálogo entre o conhecimento científico e os saberes dos trabalhadores. O termo "pesquisa" já vinha sendo utilizado no Brasil fora de uma concepção acadêmica stricto senso. Note-se que Freire ${ }^{1}$ já fazia uso da expressão "círculos de investigação temática” para falar do dispositivo de formação baseado no debate entre saberes distintos.

Sob esse prisma, ao focalizar-se a questão em torno da tríade vida, saúde e trabalho, entendemos que o processo de inserção dos trabalhadores em um dispositivo de compreensão $\leftrightarrow$ transformação, instituindo um espaço dialógico facilitador do debate entre experiência e conhecimento científico, não deve apreendê-los como consumidores passivos. Eles não são meros aprendizes-repetidores do que ouvem dos profissionais de formação e investigação ${ }^{1}$. Trata-se, em verdade, de aprendizagem recíproca, com base em suas culturas e inculturas mútuas ${ }^{24}$, com a possibilidade de realização na prática dessa confrontação, validando ou não e desenvolvendo as informações e os conteúdos disponibilizados e debatidos.

Vimos, portanto, que para impulsionar o dispositivo CAPI era fundamental reconhecer a não neutralidade da linguagem e que, na atividade dialógica, conceitos e categorias usados tanto pelos trabalhadores quanto pelos pesquisadores podem resultar em qualificação ou desqualificação dos saberes em debate. Por essa razão, passamos a afirmar que é preciso fazer circular na CAPI uma comunidade dialógica de pesquisa voltada à análise do trabalho. Assumir essa perspectiva de comunidade dialógica de pesquisa ${ }^{34}$ significa o reconhecimento da tensão constitutiva da linguagem e da interação como lugar de construção permanente de identidades, de posicionamentos e de desenvolvimento de sentidos. Significa ir além dos a priori pensados como compartilhados entre os coletivos de trabalho e de pesquisa, lugar de articulações e tensionamentos entre macro e micropolíticas.

Faïta $^{35}$, enquanto linguista de situações de trabalho, chama atenção não apenas para a necessidade de a linguagem ser abordada com o objetivo de se investigar o trabalho, mas para o quanto a investigação nesse contexto ensina sobre a linguagem como lugar de desenvolvimento de experiências ao mesmo tempo singulares e coletivas. Cada contexto requer uma estratégia, numa sucessão de experiências entre pesquisadores e trabalhadores que leva à criação de dispositivos visando promover, pode-se assim definir, um circuito dialógico. Nessa direção, a comunidade dialógica de pesquisa ${ }^{34}$ é proposta como conceito-provisório de um posicionamento ético e epistemológico com respeito ao lugar da linguagem na pesquisa, à formação e à intervenção em saúde do trabalhador. Isso implica estimular relações dialógicas intensas; incrementar o diálogo entre o registro da experiência e o registro do conhecimento científico; priorizar interações verbais, que são de modo concomitante a intersecção de atividades e experiências; fazer circular as vivências simultaneamente coletivas e singulares, envolvendo os sujeitos (o que inclui os pesquisadores) em uma dinâmica da construção de sentidos e de conhecimentos ${ }^{36}$.

Assim, no caso específico do Programa de Formação, Gênero e Trabalho nas Escolas, realizado em parceria entre instituições acadêmicas (Escola Nacional de Saúde Pública Sergio Arouca, da Fundação Oswaldo Cruz, Universidade do Estado do Rio de Janeiro, Universidade Federal da Paraíba, Universidade Federal Fluminense e Universidade Federal do Estado do Rio de Janeiro) e sindicatos (Sindicato Estadual dos Profissionais de Educação do Rio de Janeiro e Sindicato dos Trabalhadores em Educação do Município de João Pessoa) no estado do Rio de Janeiro e no município de João Pessoa (PB), no período de 2001 a 2010, o principal objetivo era desenvolver um dispositivo mais apropriado do que aqueles que mobilizávamos até então ${ }^{30-33}$. O intuito era o de intervir na problemática da precarização das situações de trabalho nas redes públicas de ensino em sua relação com o processo saúde-doença das trabalhadoras de escola (professoras, cozinheiras escolares, auxiliares de serviços gerais, secretárias, coordenadoras, orientadoras pedagógicas, diretoras etc.). Como dito anteriormente, foi a partir dessa experimentação que se desenvolveu o dispositivo CAPI. O direcionamento realizado pelo programa em questão esteve em convergência com o paradigma da formação dos atores na e pela análise do trabalho, para e pela ação, calcado em pesquisas e estudos ergonômicos ${ }^{37}$. Procurou-se empreender um processo formativo com base no engendramento de dispositivos de análise e de transformação do trabalho conduzido pelas próprias trabalhadoras (investindo-se em sua capacidade de investigação), em diálogo com os pesquisadores profissionais, com vistas à promoção da saúde.

O Programa de Formação foi concebido, portanto, como um elemento para desenvolver a capacidade 
de compreender $\leftrightarrow$ transformar as relações entre o trabalho na escola e o processo saúde-doença, a partir do diálogo-confrontação entre o conhecimento científico e o saber oriundo da experiência concreta (prática) das trabalhadoras. Delineou-se um dispositivo de formação para pesquisa-intervenção em rede: um programa de formação vinculado a um programa de pesquisas. Isto é, uma formação direcionada para a ação compreensivo $\leftrightarrow$ transformadora, integrando aí a ótica das relações sociais de gênero ${ }^{38-41}$, cuja finalidade, em última instância, seria a luta pela saúde e a afirmação da potência da vida. A expectativa era que a participação nesse programa colaborasse para sensibilizar o olhar e a escuta das trabalhadoras (e dos profissionais de pesquisa) quanto aos problemas da escola na lida com a sua saúde e, ainda, que contribuísse para a descoberta de alternativas para a constituição de um trabalho capaz de compatibilizar produtividade e qualidade com saúde e segurança ${ }^{30-33}$.

\section{Considerações finais}

Torna-se importante, à guisa de conclusão do texto, abordar de modo mais detido uma das questões com a qual nos defrontamos a partir, mas não somente, das nossas experiências de pesquisa, formação e intervenção. Tal questão diz respeito às expectativas dos trabalhadores acerca das transformações no trabalho. O profissional que realiza a intervenção deve se ater à apresentação de relatórios/dossiês de pesquisa, esperando que os trabalhadores assumam plenamente a dianteira do processo de transformação concreta das situações de trabalho? Ou ele deve, de outra maneira, participar efetivamente da construção das condições políticas da transformação? Como lidar com o fato de que a intervenção começa, não raro, com uma determinada política de gerenciamento, que vem acompanhada da possibilidade de uma mudança nas condições de trabalho, e de que durante o processo tal política é alterada, e a gerência substituída?

A nosso ver, essas questões se relacionam profundamente com as discussões da ética e da construção da demanda. Num país como o Brasil, onde a constituição de um Estado de bem-estar social ainda é uma quimera, onde a maioria da população não tem acesso a serviços públicos de educação e saúde de qualidade, onde o clientelismo e o populismo prevalecem como práticas de manipulação política, é imprescindível redobrar a prudência no modo como se propõem pesquisas e intervenções no trabalho para não se construírem expectativas infundadas. A necessidade das práticas de formação nesse contexto se amplia. Isso porque as intervenções, mesmo quando não logram os resultados de transformação concreta das situações de trabalho dentro dos prazos esperados pelos demandantes, favorecem uma mudança no modo como os trabalhadores encaram sua saúde e seu trabalho e lutam para transformá-lo coletivamente. Há um patrimônio dessas experiências que nenhuma gerência pode retirar, que é o fortalecimento da capacidade de reflexão e de ação coletiva dos trabalhadores.

Dessa forma, nossa implicação diz respeito a uma perspectiva de formação e transformação social que aglutine cooperações e diálogos para o fortalecimento das lutas pela mudança dos meios de vida, saúde e de trabalho, enfrentando alguns dos obstáculos e questões que surgem a partir das intervenções concretas. Nessa direção, os protagonistas do trabalho não são considerados unicamente "agentes" produtivos, mas fundamentalmente cidadãos, de tal forma que a finalidade das nossas intervenções não se circunscreve apenas ao nível da empresa/organização, mas procura contribuir para que a mudança de postura na forma de encarar o trabalho, malgrado seus limites, possa se somar aos elementos que compõem as forças de potencialização da vida e da saúde.

Essa tarefa tem nos exigido um rigor tanto no que se refere ao modo de construção social das pesquisas-intervenções, articuladas a estratégias de formação, como também no modo de nos apropriarmos, coletivamente, dos conceitos e de trabalhá-los. Isso demonstra a valorização de um patrimônio comum de conceitos, mas, principalmente, de uma perspectiva ética e epistemológica segundo a qual o estudo da atividade de trabalho humana e da vida/saúde dos trabalhadores só é possível por intermédio do diálogo e da colaboração entre disciplinas e saberes diferentes. Esperamos que este seja visto como um texto-convite para novos diálogos endereçados não apenas aos que têm sido nossos parceiros mais frequentes, mas também aos novos interlocutores que, com suas críticas e sugestões, certamente, contribuirão para o nosso desenvolvimento profissional.

\section{Contribuições de autoria}

Todos os autores contribuíram igualmente na elaboração e aprovação final do texto publicado. 


\section{Referências}

1. Freire P. Pedagogia do oprimido. $17^{\mathrm{a}}$ edição. Rio de Janeiro: Paz e Terra; 1987.

2. Brandão CR. Educação popular. São Paulo: Brasiliense; 1984.

3. Bezerra A. As atividades em educação popular. In: Brandão CR. A questão política da educação popular. São Paulo: Brasiliense; 1980. p. 16-39.

4. Garcia PB. Educação popular: algumas reflexões em torno da questão do saber. In: Brandão CR. A questão política da educação popular. São Paulo: Brasiliense; 1980. p. 88-121.

5. Neves MY. Análise da prática educativa do "Projeto de Educação Integrada em Áreas rurais - Educação popular e trabalho no meio rural” [dissertação]. [João Pessoa]: Universidade Federal da Paraíba; 1990. 176 p.

6. Sader E. Quando novos personagens entraram em cena: experiência e lutas dos trabalhadores da grande São Paulo (1970-1980). Rio de Janeiro: Paz e Terra; 1988.

7. Laurell AC, Noriega, M. Processo de produção e saúde: trabalho e desgaste operário. São Paulo: Hucitec; 1989.

8. Seligmann-Silva E. Trabalho e desgaste mental: o direito de ser dono de si mesmo. São Paulo: Cortez; 2011.

9. Marx K. O capital: crítica da economia política. $3^{\mathrm{a}}$ ed. São Paulo: Nova Cultural; 1988. (vol. 1).

10. Minayo-Gomez C, Lacaz FAC. Saúde do trabalhador: novas-velhas questões. Cien Saúde Colet. 2005;10(4):797-807.

11. Minayo-Gomez C. Campo da saúde do trabalhador: trajetória, configuração e transformações. In: MinayoGomez C, Machado JMH, Pena PGL. Saúde do trabalhador na sociedade brasileira contemporânea. Rio de Janeiro: Fiocruz; 2011. p. 23-34.

12. Lacaz FAC. O campo Saúde do Trabalhador: resgatando conhecimentos e práticas sobre as relações trabalho-saúde. Cad Saúde Pública. 2007;23(4):757-66.

13. Minayo-Gomez C, Thedim-Costa S. A construção do campo da saúde do trabalhador: percurso e dilemas. Cad Saúde Pública. 1997;13(Supl. 2):21-32.

14. Oddone I, Re A, Briante G. Redécouvrir l'expérience ouvrière: vers une autre psychologie du travail? Paris: Messidor/Éditions Sociales; 1981.

15. Brito J. Saúde do trabalhador: reflexões a partir da abordagem ergológica. In: Figueiredo M, Athayde M, Brito J, Alvarez D. Labirintos do trabalho: interrogações e olhares sobre o trabalho vivo. Rio de Janeiro: DP\&A Editora; 2004. p. 91-114.

16. Muniz HP, Brito J, Souza KR, Athayde M, Lacomblez MH. Ivar Oddone e sua contribuição para o campo da saúde do trabalhador no Brasil. Rev Bras Saúde Ocup. 2013;38(128):280-91.

17. Canguilhem G. O normal e o patológico. $7^{\mathrm{a}}$ ed. Rio de Janeiro: Forense Universitária; 2011.
18. Dejours C, Dessors D, Desriaux F. Por um trabalho fator de equilíbrio. Rev Adm Empres. 1993;33(3):98-104.

19. Silva E, Brito J, Neves MY, Athayde M. A promoção da saúde a partir das situações de trabalho: considerações referenciadas em uma experiência com trabalhadores de escolas públicas. Interface (Botucatu) [online]. 2009;13(30):107-19.

20. Teiger C, Daniellou F. Formation à l'analyse de l'activité et rapport au travail. In: Dejours C. Plaisir et souffrance dans le travail. Paris: Aocip; 1987. p. 77-94.

21. Wisner A. A inteligência no trabalho: textos selecionados de ergonomia. São Paulo: Fundacentro; 1994.

22. Falzon P, organizador. Ergonomia. São Paulo: Edgard Blücher; 2007.

23. Duraffourg J. Assembler les pièces du puzzle. Les territoires du travail. 1999;3:71-8.

24. Schwartz Y. Le paradigme ergologique ou un métier de philosophe. Toulouse: Octarès; 2000.

25. Schwartz Y, Durrive, L, organizadores. Trabalho e ergologia: conversas sobre a atividade humana. $2^{\text {a }}$ ed. Niterói: EdUFF; 2010.

26. Schwartz Y. Trabalho e gestão: níveis, critérios, instâncias. In: Figueiredo M, Athayde M, Brito J, Alvarez D. Labirintos do trabalho: interrogações e olhares sobre o trabalho vivo. Rio de Janeiro: DP\&A Editora; 2004. p. 23-33.

27. Teiger C, Laville A, Duraffourg J. Tâches répétitives sous contrainte de temps et charge de travail: étude des conditions de travail dans un atelier de confection. Paris: Conservatoire National des Arts et Métiers; 1973. (Collection du Laboratoire de Physiologie du Travail - Ergonomie; Rapport; n. 39).

28. Teiger C. L'approche ergonomique: du travail humain à l'activité des hommes et des femmes au travail. Education Permanente. 1993;116:71-96.

29. Schwartz Y. A comunidade científica ampliada e o regime de produção de saberes. Trab Educ. 2000;7:38-46.

30. Brito J, Athayde M, Neves MY, organizadores. Cadernos de textos: Programa de Formação em Saúde, Gênero e Trabalho nas Escolas. João Pessoa: Editora UFPb; 2003.

31. Brito J, Athayde M. Trabalho, educação e saúde: o ponto de vista enigmático da atividade. Trab Educ Saúde. 2003;1(2):63-89.

32. Athayde M, Zambroni-Souza PC, Brito J. Intervenção e pesquisa em psicologia: uma postura ergológica. In: Bendassolli PF, Soboll LAP. Métodos de pesquisa em psicologia do trabalho: clínicas do trabalho. São Paulo: Atlas; 2015. p. 129-57.

33. Neves MY, Muniz HP, Silva EF, Costa JD, Brito J, Athayde M. Saúde, gênero e trabalho nas escolas públicas: potencialidades e desafios de uma experiência com o dispositivo "Comunidade 
Ampliada de Pesquisa e Intervenção”. Laboreal. 2015;11(1):53-68.

34. França MB. Uma comunidade dialógica de pesquisa: atividade e discurso em guichê hospitalar. São Paulo: Educ; 2008.

35. Faïta D. Análise dialógica da atividade profissional. Rio de Janeiro: Imprinta; 2005.

36. Alvarez D, França MB, Figueiredo M. Exercício analítico sobre o método: aspectos linguageiros na atividade dialógica com trabalhadores de exploração e produção no setor petrolífero. Laboreal. 2015;11(1):39-52.

37. Teiger C, Lacomblez, M, organizadores. (Se) Former pour transformer le travail: dynamiques de constructions d'une analyse critique du travail. Québec: PUL/ETUI; 2013.

38. Hirata H, Kergoat D. Rapports sociaux de sexe et psychopathologie du travail. In: Dejours C. Plaisir et souffrance dans le travail. Paris: Éditions de l'Aocip; 1988. p. 131-76. (Tome II).

39. Hirata H. Paradigmes du travail, un "point de vue transversal”. Futur Antérieur. 1993;16:5-10.

40. Kergoat D. A relação social de sexo: a reprodução das relações sociais à sua subversão. Pro-posições. 2002;13(1):47-59.

41. Brito J. Saúde, trabalho e modos sexuados de viver. Rio de Janeiro: Fiocruz; 1999. 